principle as applied in acoustics, we find four cases: (I) approach of observer, source and medium being at rest ; (2) recession of observer, source and medium at rest ; (3) approach of source, observer and medium at rest; (4) recession of source, observer and medium at rest.

I have consulted all the standard authorities which have occurred to me, and find they all agree in the Ist and 2 nd cases. In (3), Doppler, Lord Rayleigh, Prof. Everett (Ist method in "Deschanel "), Jamin, and Ganot have the same result as in (I). Lord Rayleigh in his "Theory of Sound," vol. ii. p. 142, says, "In the case of a periodic disturbance a velocity of approach $v$ " is equivalent to an increase of frequency in the ratio $a: a+v, " a$ being the velocity of sound. In another place the same author says that it is the relative velocity of source and observer alone that is important. The above-mentioned authorities appear to hold the same views.

But Prof. Everett has a more rigorous demonstration than the above, which leads to the result-old pitch : new pitch :: $a-v: a$. This result is the same as that given by Mach, "Ton u. Färberänderung durch Bewegung "( $\left(8_{74}\right)$, and as that used by Balfour Stewart, "Treatise on Heat."

In the $4^{\text {th }}$ case the first-mentioned authors again agree, giving as a result-new pitch : old pitch :: $a: a-v$. Prof. Everett's and E. Mach's results agree in giving $a+v: a$ as the ratio.

It will be readily admitted that the first two cases are simpler problems to attack than the last two. The results of the minority for the cases (3) and (4) seem to me to come from looking at the change in wave-length first, those of the majority from taking into account the number of waves met by the observer. In any case the disagreement among such authorities is naturally beyond me to explain. The motion of the medium does not appear to offer any special difficulty.

G. H. Wyatt.

The Relative Prevalence of North-east and South-west Winds.

THE direction of the wind has been noted twice daily at this Observatory (9 a.m. and 9 p.m.) during the past 6 years, with the following mean results :-

N. N.E, E. S.E. S. S.W. W. N.W. Calm,

The period under consideration is not sufficiently long to make the series of observations of any great value, but as Mr. Ellis asks for comparison₹, I am happy to give them for what they are worth.

Rousdon Observatory, Lyme Regis, April 26.

\section{The London Mathematical Society's List of Papers.}

IN NATURE (vol. xli. p. 594) it is stated that " a complete index of the papers printed in the Proceedings of the London Mathematical Society has been issued." It will be in the recollection of some that a previous issue of the Index to the papers contained in the first I7 volumes was announced in Nature (vol. xxxvi. p. 42): it is a re-issue of this list completed for the first 20 volumes that is now noted. The former edition of 3000 copies was soon dispersed, and resulted in warm expressions of thanks from mathematicians, and also in an increased sale of the Proceedings. If other Societies would, in like manner, issue lists of the titles of papers printed in their Proceedings, they would no doubt meet with a like reward. All mathematicians, and others who are interested in mathematical research, can have a copy on application to the Secretaries (22 Albemarle Street, W.), or to the publisher (Francis Hodgson, 89 Farringdon Street, E. C.).

April 26.

R. Tucker, Hon. Sec.

THE UNITED STATES SCIENTIFIC EXPEDITION TO WEST AFRICA, I889.

$A \mathrm{~S}$ the work of the Expedition approaches conclusion,

I venture to hope that a brief partial recital of results may be worth notice in NATURE, particularly as, in many of the ports we have visited, English courtesy and English hospitality have contributed in large measure to the facilities for prosecuting our work, not to say also very greatly to the delight of doing it.

I find it a trifle difficult to say just where to begin, but Dr. David Gill, H.M. Astronomer at the Cape, comes first to mind, and surely no one could have devoted himself more unsparingly to the interests of the Expedition than he did during our stay of a fortnight and more at Cape Town: and through his liberal provision for every requirement of the observers, it became possible to swing the pendulums in the Royal Observatory buildings, the same spot occupied in previous gravity-research at the Cape. Had it been expedient to delay the Pensacola longer, Dr. Gill's suggestion would gladly have been acted upon, and an additional gravity-determination made at the Kimberley diamond fields, 650 miles in the interior, at an elevation of about 4000 feet; but there was time only for members of the Expedition not engaged in exact measures to proceed as far inland as that; and the movements and operations of the naturalists and others who desired to visit the Cape Colony country as far as Kimberley became feasible through the kind offers of Mr. Difford, the Secretary of the Colonial Government Railways.

Not only at Cape Town had we much occasion to thank His Excellency Sir H. B. Lock, the Governor of the Colony, but two months later, at Ascension Island, through his courteous intervention, and the obliging civilities of Admiral Wells, R.N., all possible preparation had been made; while, on our arrival, Captain Napier, R.N., in charge of Ascension. most thoughtfully smoothed the way by arranging to our entire satisfaction all matters which could in any way facilitate the work we had planned for that interesting island.

Nor am I forgetting the multitude of courtesies at the hands of Governor Antrobus of St. Helena, where all desired assistance was afforded, and where work similar to that at Ascension was undertaken and completed.

In this connection, I must not omit mention of the American Navy, for neither the Expedition in its present form nor its work could have become an accomplished fact but for the enlightened policy of Secretary Tracy, who assigned a man-of-war for its transport to Africa and home again ; of Admiral Walker, and later, Commodore Dewey, Chiefs of Naval Bureaux, who devoted their energies ungrudgingly to the regulation of all matters official affecting the welfare of the Expedition; and of Captain Yates, the commander of the U.S.S. Pensacola, who has done everything in his power to forward the prosecution of the scientific work.

The Pensacola left New York on October 16 last ; called at the ports of Horta, Fayal, Azores, November 2-3; San Vicenti, Cape Verdes, November IO-12; St. George's Parish, Sierra Leone, November 18-20 ; Elmina, Gold Coast, November 26-28; São Paolo di Loanda, December 6-7 ; Eclipse Bay, Cape Ledo, December 8--27 ; again at Loanda, December 28-January 6; Cape Town, January I7-February 6; St. Helena, February 20-March Io; and arrived at Ascension six days later, which port she will probably leave about April Io.

Now to some of the results.

At all these stations except Cape Ledo, the magnetic elements have been carefully investigated by Mr. Preston, of the U.S. Coast and Geodetic Survey. Also he had an additional magnetic station at Cabiri, about 45 miles interior from Loanda, whither he went for the immediate eclipse period.

The short time available before the eclipse made it impracticable to begin the gravity-determinations until Loanda; there Mr. Preston swung the Peirce pendulums, and again at the Royal Observatory, Cape Town. At St. Helena two complete swings were obtained, the one at a sea-level station near the Castle, Jamestown, and the other at Longwood, elevation 1750 feet. It was not 